\title{
What Is Being Played in the World? Mobile eSport Applications
}

\author{
Ahmet Atalay ${ }^{1, *}$, Arif Cem Topuz ${ }^{2}$ \\ ${ }^{1}$ School of Physical Education and Sport, Ardahan University, Turkey \\ ${ }^{2}$ Engineering Faculty, Ardahan University, Turkey
}

Copyright $\odot 2018$ by authors, all rights reserved. Authors agree that this article remains permanently open access under the terms of the Creative Commons Attribution License 4.0 International License

\begin{abstract}
In this study, the aim is to examine the most popular eSport applications at a global scale. In this context, the App Store and Google Play Store application platforms which have the highest number of users at a global scale were focused on. For this reason, the eSport applications included in these two platforms constituted the sampling of the present study. A data collection form was developed by the researcher of the study in order to collect the data in the study. This form included the number of the countries, the popularity ratings of the application, the name of the application, the type of it, the age limit, the rating of the likes, the company that developed it, the version and the first appearance date. The study was conducted with the Qualitative Research Method, and the Case Study design was made use of in this process; and the Descriptive Analysis Method was used to analyze the data. As a result of the study, it was determined that the most popular eSport applications at a global scale were football, which ranked the first, basketball, billiards, badminton, skateboarding, golf and dart. It was also determined that the popularity of the mobile eSport applications changed according to countries and according to being free or paid. It was determined that the popularity of these applications differed according to the individuals using the App Store and Google Play Store application markets. As a result, it is possible to claim that mobile eSport applications have a wide usage area at a global scale and are accepted widely. In addition, it was observed that the interest in eSport applications was similar to that in traditional sports. However, in the present study, a certain date was set, and the interest in mobile eSport applications was analyzed according to this specific date. In future studies, different dates and different fields like educational sciences may be set to analyze the interest in mobile eSport applications. In this way, findings may be obtained on the change of the interest in mobile eSport applications according to time. The findings of the present study and similar studies may have the quality of guiding researchers and system/software developers in terms of showing the present status of the topic and revealing the relevant needs.
\end{abstract}

Keywords Sport Management, eSport, Mobil eSport, Mobil Sport Applications

\section{Introduction}

Today, it is possible to claim that the most common services among the ones provided for humanity by technology are mobile devices. It is also possible to claim that among the mobile devices; almost each individual has at least one smart phone which is used in an efficient manner. One of the tools that constitute the communicational network of people in the whole world is smart phones. However, smart phones are not only communicational devices. As well as being an important communication need today, they have also been transformed into a dynamic device that helps people play games, listen to music, and provide them with navigation applications [1]. With this transformation, the data consumption of people and the variety of the data have been increased in recent years [2]. The data types are presented to people through "application markets" included in these phones. Among the application markets, the App Store and Google Play Store, which serve iOS and Android platforms, are the most prominent ones [3]. The applications presented in these markets are categorized as "paid" and "free of charge". AppStore and Google Play Store provide lots of mobil applications for users. Users can easily access many application categories and mobil applications from the application pool installed on their mobile devices.

Depending on the technological developments within the past five years, the applications in the markets in smart phones have become extremely important [1] because smart phones and the applications in them have become available all the time $[4,5]$. This availability has become to such a level that today there are more than 2 million applications in Android and iOS platforms [6]. For this 
reason, with the help of smart phones, users may reach many applications according to their needs. The most prominent one among these applications is the "mobile eSport" applications [7].

eSport is a type of sports in which the primary sides of sport are facilitated by electronic systems [8]. In addition, eSport applications are also defined as virtual sport and competitive sport [9]. While mobile eSport applications are perceived as a free time activity, they also have a sportive identity that has a target for success. For this reason, individuals who use eSport applications in their smart phones must be able to use their reflexes, brain functions, and hand-eye coordination in an efficient manner in order to succeed [10]. In addition to this, mobile eSport applications constitute a sportive activity in which people develop their mental and physical abilities by using their knowledge and communication technologies [11]. Because of this compact structure of mobile eSport applications, eSport has gained a fast popularity and a serious followers list all over the world [12]; and for this reason, it has become a discriminative and specific field [13]. In addition to these, it has also become a phenomenon which enables people to make use of their free times and increase their online-offline experiences with activities that resemble sports with one single application [14]. For this reason, eSport has developed and has become professionalized with the help of connections between different consumption applications like playing, watching and managing [15].

\subsection{The Aim of the Study}

In the present study, the purpose was to examine the most popular mobile eSport applications at a global scale. Based on this purpose, answers were sought for the following questions.

1. What are the mobile eSport applications that rank the first at a global scale?

1.1. What are the most popular mobile eSport applications among the free applications in App Store?

1.2. What are the most popular mobile eSport applications among the free applications in Google Play Store?

1.3. What are the most popular mobile eSport applications among the paid applications in App Store?

1.4. What are the most popular mobile eSport applications among the paid applications in Google Play Store?

2. What are the general features of the most popular 5 mobile eSport applications at a global scale?

\subsection{The Importance of the Study}

Mobile eSport applications are demanded widely all over the world, and the variety of these applications is increased with each passing day. Especially the intense interest of young population is increasing in the educational, economic and social values of eSport applications. These applications, which reach millions of people with the help of smart phones, attract the attention of consumers, producers and researchers. As a matter of fact, various studies are being conducted on the applications in eSport field, which has a tremendous income and introduction potential, and whose importance is increasing day by day [16]. The mobile eSport applications, which are not mere digital applications, and which have the properties of traditional sports, also have sociological contents [11].

With its economic and social values, eSport has become an important argument among educational curricula and programs. As a matter of fact, eSport has been included in educational curricula mainly in Asian countries and also in the USA, Sweden, Norway; and has also been included in many scholarship programs [17]. For this reason, eSport has a commercial identity and has also been included in the economic, social and educational plans and programs of countries. For this reason, it is important that the present status and prevalence of mobile eSport applications with scientific data. Depending on the constant development of technology, mobile eSport has reached a global spread and has been accepted widely.

\subsection{The Limitations of the Study}

The popularity rating of the applications in the App Store and Google Play Store may show variations even within one single day at the global scale. For this reason, a certain day was selected in the study, and the popularity data within that specific day were analyzed. In this respect, the findings of the study are limited to the data obtained from the App Store and Google Play Store application markets on 15.01.2018.

\section{Materials \& Methods}

\subsection{The Study Model}

The present study was conducted with the Qualitative Research Method, and the Case Study design was made use of in this process. The Descriptive Analyses Method was applied to the data obtained in the study.

While the Qualitative Research Method enables researchers to understand, recognize and explain possible effects of the results of the natural environment where research is conducted; the researcher follows a process which goes towards the whole from pieces with a holistic image $[18,19]$. The Case Study design in Qualitative Research Method enables researchers to examine an up-to-date issue in a systematic and detailed manner, and one of the data collection techniques in this design is the examination of existing documents $[20,21]$. In the present 
study, the Descriptive Analysis Method was used in analyzing the documents obtained about the mobile eSport applications. The Descriptive Analysis helps to analyze the existing literature in a comprehensive manner, and meanwhile, it also enables researchers to examine verbal, written and other materials in an objective and systematic manner [22, 23].

\subsection{The Universe-sampling}

This study was designed on the examination of mobile eSport applications. Right at this point, the application platforms, which had the highest number of users at a global scale, App Store and Google Play Store, were focused on. For this reason, the mobile eSport applications in these platforms constituted the sampling of the study.

\subsection{Data Collection Tool}

In the present study, the data on the mobile eSport applications were collected with the data collection form, which was prepared by the researchers. This form included the following titles; number of countries, popularity rating of the application, name of the application, type of game, age limit, the rating of likes, the developer company, the size, the version, and the first release date.

\subsection{The Collection of the Data}

The data of the present study, which was conducted to examine the most popular mobile eSport applications at a global scale, were collected over the App Store and Google Play Store on 15.01.2018. Since the rating data received from the application markets vary daily, the local time of the country was considered when the data on mobile eSport applications were collected. With the help of commercial software that archives detailed data on mobile eSport applications in all markets, the data on the most popular mobile eSport applications were collected on 15.01.2018. In order to reach the data, a commercial website was used where information on all mobile applications on a global scale was recorded on a daily basis. The sports category has been selected among all mobile applications included in this website. Then, AppStore and the Google Play Store named application pool were selected. After that, filtering was done according to paid and free eSpor applications. The collected data were classified through the data collection form.

\subsection{The Analysis of the Data}

The Descriptive Statistical Methods were made use of in the analyses of the data obtained in the scope of the present study, which was conducted on the most popular mobile eSport applications. The data on the most popular mobile
eSport applications at a global scale were written on the data collection form, and the study findings were achieved with the help of frequency values.

\section{Findings}

The findings that were obtained with the processing of the data that were collected in the study are presented in this part. In this context, firstly, the findings on the most popular mobile eSport applications at a global scale are given. Then, the findings on the mobile eSport applications that rank within the first five at a global scale are provided in this part.

Table 1. The most popular mobile eSport applications among the free applications in App Store Application Market

\begin{tabular}{|c|c|c|c|}
\hline eSpor Application & Country* & eSpor Application & Country* \\
\hline $\begin{array}{c}\text { Dream League } \\
\text { Soccer } 2018 \\
\end{array}$ & 33 & Big Shot Boxing & 1 \\
\hline 8 Ball Pool ${ }^{\mathrm{TM}}$ & 32 & Bike Race: Mad Riding & 1 \\
\hline FIFA Soccer & 14 & Dominoes Elite & 1 \\
\hline Infinite Golf & 10 & $\begin{array}{c}\text { Drift Max Pro - Drifting } \\
\text { Game }\end{array}$ & 1 \\
\hline Badminton League & 6 & EA SPORTSTM UFC@ & 1 \\
\hline Dunk Hit & 5 & $\begin{array}{c}\text { Gas Station 2: Highway } \\
\text { Service }\end{array}$ & 1 \\
\hline Dunk Hoop & 5 & GOAL DX & 1 \\
\hline Biathlon Mania & 4 & MADDEN NFL Football & 1 \\
\hline Flappy Dunk & 4 & Merge Pool & 1 \\
\hline Football Strike & 4 & $\begin{array}{c}\text { Offroad } 4 \times 4 \text { Truck Trials } \\
\text { Parking Simulator } \\
\end{array}$ & 1 \\
\hline Dunk a Lot! & 3 & Physics Balls & 1 \\
\hline Golf Clash & 3 & Pro Darts 2018 & 1 \\
\hline $\begin{array}{c}\text { PES } 2018 \text { Pro } \\
\text { Evolution Soccer }\end{array}$ & 3 & $\begin{array}{l}\text { RC Club - AR } \\
\text { Motorsports }\end{array}$ & 1 \\
\hline $\begin{array}{c}\text { Dumb Ways to Die } \\
\text { 2: The Games }\end{array}$ & 2 & Score! Hero & 1 \\
\hline $\begin{array}{c}\text { NBA LIVE Mobile } \\
\text { Basketball }\end{array}$ & 2 & Ski Jump Challenge & 1 \\
\hline $\begin{array}{l}\text { Pool Elite: 3D } \\
\text { Billiards }\end{array}$ & 2 & Soccer Manager 2018 & 1 \\
\hline $\begin{array}{c}\text { World Cricket } \\
\text { Championship } 2\end{array}$ & 2 & $\begin{array}{c}\text { Top Football Manager - } \\
\text { Soccer }\end{array}$ & 1 \\
\hline Basketball Stars $^{\mathrm{TM}}$ & 1 & Total Snooker & 1 \\
\hline Big Bash Cricket & 1 & تحدي الهوكي 2 - لعبة رياضية & 1 \\
\hline
\end{tabular}

* The number of countries in which the eSport application is ranked first.

When Table 1 given above is examined it is understood that the most popular mobile eSport applications at a global scale among the free applications in the App Store are football and billiards games like "Dream League Soccer 2008", "8 Ball Pool" and FIFA Soccer". When the most popular applications are considered in the context of countries, it is understood that the interest intensified on mainly eSport applications like football, golf, badminton and basketball. 
When Table 2 given below is examined it is understood that the most popular mobile eSport applications at a global scale among the free applications included in Google Play Store application market are football and billiards games like "FIFA Soccer", "8 Ball Pool" and "Billiards City". When the most popular applications are considered in a country-based manner, it is seen that the interest of consumers who made use of mobile eSport applications intensified in badminton and dart after football and billiards.
When Table 3 given below is examined it is understood that the most popular mobile eSport applications at a global scale among the paid applications in App Store application market are basketball, football and skateboarding games like "NBA JAM", "Football Manager Mobile 2018", "True Skate" and "NBA2K18". When the most popular paid applications are considered in a country-based manner, it is understood that the games like fight, adventure, athletics and table tennis attract interest, which is different from the free applications in App Store.

Table 2. The most popular mobile eSport applications among the free applications in Google Play Store Application Market

\begin{tabular}{|c|c|c|c|}
\hline eSpor Application & Country* & eSpor Application & Country* \\
\hline FIFA Soccer & 46 & Offline Challenge 18 & 1 \\
\hline 8 Ball Pool & 23 & Score! Hero & 1 \\
\hline Billiards City & 11 & Ski Jump & 1 \\
\hline Badminton League & 3 & Slingshot Championship & 1 \\
\hline Darts Match 2 & 3 & Snowboarding The Fourth Phase & 1 \\
\hline Football Strike & 3 & Soccer Stars & 1 \\
\hline Baseball Star & 1 & Tappy Shots & 1 \\
\hline Basketball Dunk Tournament & 1 & World Cricket Championship Lt & \\
\hline Big Bash Cricket & 1 & みんゴル & \\
\hline Flip Master & 1 & & \\
\hline
\end{tabular}

* The number of countries in which the eSport application is ranked first.

Table 3. The most popular mobile eSport applications among the paid applications in App Store Application Market

\begin{tabular}{|c|c|c|c|}
\hline eSpor Application & Country* & eSpor Application & Country* \\
\hline NBA JAM by EA SPORTSTM & 22 & Beach Volley Pro & 1 \\
\hline Football Manager Mobile 2018 & 21 & Bow master & 1 \\
\hline True Skate & 15 & Cricket WorldCup Fever Deluxe & 1 \\
\hline NBA 2 K18 & 13 & Desert Golfing & 1 \\
\hline Real Steel & 7 & Figure Skater & 1 \\
\hline Alto's Adventure & 6 & Flick Kick Football & 1 \\
\hline Summer Games 3D & 6 & Flight Simulator FlyWings 2014 HD & 1 \\
\hline World Cup Table Tennis ${ }^{\mathrm{TM}}$ & 5 & Football Chairman Pro & 1 \\
\hline Superstar Soccer: Goal & 4 & Go! Medina & 1 \\
\hline Skater & 3 & In-Flight Assistant & 1 \\
\hline 3D Pool Game Plus & 2 & iBasket Pro- Street Basketball & 1 \\
\hline Aqua Moto Racing & 2 & Mad Skills BMX & 1 \\
\hline Colin McRae Rally & 2 & Monoposto & 1 \\
\hline Deer Hunter: African Safari & 2 & R.B.I. Baseball 17 & 1 \\
\hline iBoat Racer & 2 & Race Horses Champions for iPhone & 1 \\
\hline iStunt 2 - Snowboard & 2 & Rugby League Live 2: Quick Match & 1 \\
\hline Matt Duchene's Hockey Classic & 2 & Rugby Nations 18 & 1 \\
\hline Parkour Flight & 2 & Soccer Real Stars '17 & 1 \\
\hline Pixel Cup Soccer 16 & 2 & Super Badminton & 1 \\
\hline Real Tennis 2018 & 2 & Sure Win Bet Calculator & 1 \\
\hline Soccer 17 & 2 & Touchgrind BMX & 1 \\
\hline 10 Pin Shuffle Pro Bowling & 1 & Trial Xtreme 1 & 1 \\
\hline 2XL Snocross & 1 & Trial Xtreme 2 Winter Edition & 1 \\
\hline 2XL Supercross & 1 & Vegas Pool Sharks & 1 \\
\hline Aqua Moto Racing 2 & 1 & 常夏プールパレス & 1 \\
\hline Backflip Madness & 1 & & \\
\hline
\end{tabular}

\footnotetext{
* The number of countries in which the eSport application is ranked first.
} 
Table 4. The most popular mobile eSport applications among the paid applications in Google Play Store Application Market

\begin{tabular}{|c|c|}
\hline eSpor Application & Country* \\
\hline Football Manager Mobile 2018 & 87 \\
\hline NBA 2K18 & 6 \\
\hline True Skate & 3 \\
\hline Desert Golfing & 1 \\
\hline Football Agent & 1 \\
\hline OK Golf & 1 \\
\hline
\end{tabular}

* The number of countries in which the eSport application is ranked first.
When Table 4 is examined, it is seen that the most popular paid mobile eSport applications at a global scale included in Google Play Store application market are football, basketball and skateboarding games like "Football Manager Mobile 2018", "NBA2K18" and "True Skate". When the most popular games are considered at a country-based manner, it is understood that football, basketball, skateboard, and golf games are preferred by users.

Table 5. The Features of the Most Popular 5 Mobile eSport Applications at a Global Scale

\begin{tabular}{|c|c|c|c|c|c|c|c|c|c|c|}
\hline & & eSport Application & $\begin{array}{c}\text { number of } \\
\text { countries }\end{array}$ & $\begin{array}{c}\text { popularity } \\
\text { rating } \\
\end{array}$ & $\begin{array}{l}\text { type of } \\
\text { game }\end{array}$ & $\begin{array}{c}\text { Age } \\
\text { limit } \\
\end{array}$ & \begin{tabular}{|c|} 
the rating \\
of likes
\end{tabular} & $\begin{array}{l}\text { the developer } \\
\text { company }\end{array}$ & the size & the version \\
\hline \multirow{10}{*}{$\begin{array}{l}\text { App } \\
\text { Store }\end{array}$} & \multirow{5}{*}{ Ücretsiz } & \begin{tabular}{|c|} 
Dream League Soccer \\
2018 \\
\end{tabular} & 33 & 1 & Futbol & $4+$ & 4.5 & $\begin{array}{l}\text { First Touch } \\
\text { Games }\end{array}$ & $410,5 \mathrm{MB}$ & 8.0 and up \\
\hline & & 8 Ball Pool ${ }^{\mathrm{TM}}$ & 32 & 2 & Bilardo & $4+$ & 4.2 & Miniclip.com & $86.8 \mathrm{MB}$ & 7.0 and up \\
\hline & & FIFA Soccer & 14 & 3 & Futbol & $4+$ & 4,2 & Electronic Arts & $94 \mathrm{MB}$ & 4.1 and up \\
\hline & & Infinite Golf & 10 & 4 & Golf & $12+$ & 4,1 & Voodoo & $26,6 \mathrm{MB}$ & 8.0 and up \\
\hline & & Badminton League & 6 & 5 & Badminton & $4+$ & 4,6 & RedFish Games & $66,4 \mathrm{MB}$ & $\begin{array}{l}4.0 .3 \text { and } \\
\text { up }\end{array}$ \\
\hline & \multirow{5}{*}{ Ücretli } & $\begin{array}{l}\text { NBA JAM by EA } \\
\text { SPORTSTM }\end{array}$ & 22 & 1 & Basketbol & $4+$ & 3,3 & Electronic Arts & $407 \mathrm{MB}$ & 8.0 and up \\
\hline & & $\begin{array}{l}\text { Football Manager } \\
\text { Mobile } 2018 \\
\end{array}$ & 21 & 2 & Futbol & $4+$ & 4,7 & SEGA & $1,1 \mathrm{~GB}$ & 8. 0 and up \\
\hline & & True Skate & 15 & 3 & Kaykay & $4+$ & 4.2 & True Axis & $134,6 \mathrm{MB}$ & 8.0 and up \\
\hline & & NBA 2 K18 & 13 & 4 & Basketbol & $4+$ & 3,2 & $2 \mathrm{~K}$ & $3,1 \mathrm{~GB}$ & 9.0 and up \\
\hline & & Real Steel & 7 & 5 & $\begin{array}{l}\text { Robot } \\
\text { Dövüşü }\end{array}$ & $9+$ & 3.1 & Reliance Big Ent. & $1,3 \mathrm{~GB}$ & 8.0 and up \\
\hline \multirow{12}{*}{$\begin{array}{c}\text { Google } \\
\text { Play }\end{array}$} & \multirow{6}{*}{ Ücretsiz } & FIFA Soccer & 46 & 1 & Futbol & $4+$ & 4,2 & Electronic arts & $94 \mathrm{MB}$ & 4.1 and up \\
\hline & & 8 Ball Pool & 23 & 2 & Bilardo & $4+$ & 4,5 & Miniclip.com & $86,8 \mathrm{MB}$ & $\begin{array}{c}4.0 .3 \text { and } \\
\text { up }\end{array}$ \\
\hline & & Billiards City & 11 & 3 & Bilardo & $4+$ & 4,5 & Mountain game & $32 \mathrm{MB}$ & $\begin{array}{l}4.0 .3 \text { and } \\
\text { up }\end{array}$ \\
\hline & & Badminton League & 3 & 4 & Badminton & $8+$ & 4,6 & RedFish Games & $66,4 \mathrm{MB}$ & $\begin{array}{c}4.0 .3 \text { and } \\
\text { up }\end{array}$ \\
\hline & & Darts Match 2 & 3 & 4 & Dart & $4+$ & 4,3 & PEGI & $59,9 \mathrm{MB}$ & $\begin{array}{c}4.0 .3 \text { and } \\
\text { up }\end{array}$ \\
\hline & & Football Strike & 3 & 4 & Futbol & $4+$ & 4,2 & PEGI & $40,53 \mathrm{MB}$ & $\begin{array}{c}4.0 .3 \text { and } \\
\text { up }\end{array}$ \\
\hline & \multirow{6}{*}{ Ücretli } & $\begin{array}{l}\text { Football Manager } \\
\text { Mobile } 2018\end{array}$ & 87 & 1 & Futbol & $4+$ & 4,7 & SEGA & $1,1 \mathrm{~GB}$ & 8. 0 and up \\
\hline & & NBA 2K18 & 6 & 2 & Basketbol & $4+$ & 3,2 & $2 \mathrm{~K}$ & $3,1 \mathrm{~GB}$ & 9.0 and up \\
\hline & & True Skate & 3 & 3 & Kaykay & $4+$ & 4.2 & True Axis & $134,6 \mathrm{MB}$ & 8.0 and up \\
\hline & & Desert Golfing & 1 & 4 & Golf & $4+$ & 4,4 & PEGI & 2,9 MB & 8,0 and up \\
\hline & & Football Agent & 1 & 4 & Futbol & $4+$ & 4,3 & PEGI & $13 \mathrm{MB}$ & 8.0 and up \\
\hline & & OK Golf & 1 & 4 & Golf & $8+$ & 4,3 & PEGI & $98 \mathrm{MB}$ & 8.0 and up \\
\hline
\end{tabular}


In Table 5, the features of the paid and free mobile eSport applications included in App Store and Google Play Store are given. The mobile eSport applications in the top-five included in both application pools are colored same in the table. The following findings were achieved when the features of the applications were considered in the study.

Firstly, when the free eSport applications were analyzed in this context, the mobile eSport applications such as 8 Ball Pool, FIFA Soccer and Badminton League were ranked in the top-five games both in App Store and Google Play Store. However, it was also understood that the Dream League Soccer 2018 and Infinite Golf in App Store pool, and the Billiards City, Darts Match 2 and Football Strike in Google Play Store pool ranked within the first five applications in only one pool. When the free eSport applications were analyzed, it was observed that the most preferred game types were football, billiards, golf/dart and badminton. The most important finding in this point was that the App Store users and Google Play users differed according to the game types they downloaded. As a matter of fact, it was determined that the App Store users preferred "golf"; and Google Play users preferred games like "dart". For this reason, it was observed that the users with iOS-based devices preferred playing golf and those with Android-based devices preferred playing dart.

When the free eSport applications were analyzed, it was determined that the NBA 2K18 and True Skate games were included in the first five both in App Store and Google Play Store applications. However, it was also determined that the other games aside from these games, which were rated among the first five in application markets, differed. The NBA JAM by EA SPORTS, Football Manager Mobile 2018 and Real Steel were included in the first five in App Store. The other applications included in Google Play Store among the first five were Desert Golfing, Football Agent and OK Gulf.

When the game types in paid mobile eSport applications were examined it was determined that football, basketball, skateboarding and fight games were popular in App Store; and basketball, football, skateboarding and golf applications were preferred in Google Play Store.

When the features of the Mobile eSport applications were examined, it was determined that these applications addressed mostly to children who were 4 years old and over; and only two games had the limit of being at and above 9 and 12 years of age. When the rating of likes for applications were considered, it was understood in general that they had a rating for likes between 3,5 and 4,5. In this situation, it is possible to claim that the users of the applications had a satisfaction with these applications with a rating of likes above average levels. When the producers of the applications were examined it was determined that the popular games were produced by different companies. In addition, it was also determined that the mobile eSport applications were produced in low sizes. It was also understood that the applications in the table required the 8.0 version for iOS and Android systems.

\section{Discussion}

In the present study, which was conducted to examine the most popular mobile eSport applications at a global scale, it is possible to claim that the data that had to be processed varied daily. For this reason, it was decided that one specific date would be determined, and the data on that specific date would be analyzed. According to this plan, the data on the most popular mobile eSport applications were received over commercial software in which the data included in application markets were archived for the date 15.01.2018. The popularity data were obtained with the help of the data collection tool that was developed by the researchers, and the study findings were obtained as a result of the analyses conducted on these data. In this respect;

Among the free applications included in the App Store application market, it was determined that the most popular mobile eSport applications at a global scale were games about football and billiards like "Dream League Soccer 2008", "8 Ball Pool" and FIFA Soccer". When the most popular applications were examined on a country basis in general, it was determined that the interest intensified in mobile eSport applications like football, which ranked the first, golf, badminton and basketball. The popularity analyses of Mobile eSport applications at a global scale showed that football has a pioneering role which is the case in traditional sports. As a matter of fact, according to the findings obtained in the study, it was understood that two of every three popular games were football games among the free applications in App Store application market. When we consider that social or mass interest has also intensified on football, it is natural that similar results are obtained in eSport platform. However, one of every three popular games being billiards may be associated with the fact that it is more easily available in digital medium in terms of time and place.

It was understood that the most popular mobile eSport applications among the free applications included in Google Play Store application market at a global scale were football and billiards games called "FIFA Soccer", "8 Ball Pool" and "Billiards City". When the most popular applications were examined on a country basis in general, it was determined that the interest of mobile eSport application consumers intensified on badminton and dart games after football and billiards games. Unlike App Store applications, it is possible to claim that two of the most popular games at global scale were billiards games in Google Play Store. As mentioned above, it is possible that traditional billiards being dependent on time and place may have caused that it has become common in digital medium. 
However, the interesting point here is that the most popular three mobile eSport applications are football and billiards in both application markets among free games.

It was understood that the most popular eSport applications both in App Store and Google Play Store application markets were football and billiards. Another study was conducted by Funk et al., [24] in the same field, and it was reported that one of the most popular eSport applications was football. It is possible to claim that the collective structure of football has caused that it showed similar properties in digital medium as well. As a matter of fact, $\mathrm{Li}$ [25] and Wagner [11] attracted attention to the fact that eSport applications has the same features like the actual sports done physically such as players, trainers, transfer fees, uniforms, and leagues; and stated that these applications reflected team spirit because they required team work. In addition, it attracts attention that a sport branch likes billiards, which has features that are specific to it, has been accepted in digital medium in such a level. The mental reflections of the physical sport like concentration, hand-eye coordination and timing Witkowski, [10] have come to the forefront in this sport branch. For this reason, it is possible to claim that the interest in mobile eSport applications is similar to that in traditional sports.

It was understood that among the paid applications in App Store application market, the football, basketball and skateboarding games named "NBA JAM", "Football Manager Mobile 2018", "True Skate" and "NBA2K18" were the most popular mobile eSport applications at a global scale. When the most popular paid eSport applications in App Store were examined on a country basis, it was understood that the interest was also intensified in fight, adventure, athletics, and table tennis as well as football, which is different from free applications. It was also determined that basketball was popular among the paid mobile eSport applications, and the interest also intensified on skateboarding. It was understood that among the paid applications included in Google Play Store application market, the football, basketball and skateboarding games with the names "Football Manager Mobile 2018", "NBA2K18" and "True Skate" were the most popular mobile eSport applications at a global scale. When the most popular paid eSport applications in Google Play Store were examined on a country basis, it was understood that football, basketball, skateboarding and golf games were preferred by users. Again, it was also observed that basketball and skateboarding games received interest in Google Play Store, which was also the case in App Store; and people paid a certain price to play these games.

Although the interest intensified on team games (basketball, football) in App Store and Google Play Store among the paid eSport applications, it was also observed that interest also intensified on skateboarding and golf applications as well. It is possible to claim that especially team games were in the forefront in all sports categories. As a matter of fact, eSport applications are not only limited to games and entertainment, they also cover the needs of the users such as establishing relations with their team mates and achieving their life goals [26]. As well as team games, it is possible to claim that applications like skateboarding and golf develop mental and physical competencies Wagner, [11] and are accepted widely for this reason. As a matter of fact, young generation increasingly moves away from "traditional" sports, and step into the professional world of games which may sometimes be competitive and sometimes more exciting [27].

When general features of the most popular mobile eSport applications were examined at a global scale, it was observed that the applications mostly address users who are at and over the age of 4; and only two games had the limit of being at and over 9 and 12 years of age. When the ratings of the games in terms of likes they received were examined it was determined that in general they had a rating between 3,5 and 4,5. In this respect, it is possible to claim that the users of the applications were satisfied at a rate that was over the average level. It was understood that the producers of the applications were different companies. Again, it was also observed that mobile eSport applications were produced at a low size. This situation might be accepted as an encouraging factor because such applications occupy very low space in the memories of smart mobile phones. The software of the smart phones is continuously updated for the satisfaction of the users and to ensure that the applications work without problems. With these updates, it was understood in the present study that the applications given in the table required version 8.0 iOS and Android. This situation may be interpreted as it is also necessary for producers of the applications to update the game versions in a continuous manner.

Mobile eSport applications have acquired an identity both as a game-entertainment and as a sportive activity all over the world. Although eSport has a high economic value at a global scale, they also attract attention because of their educative and social roles with each passing day. Such applications have become the focal point of investments especially in recent years with the increasing technological developments because these applications have a great added value in economic terms. Together with its expanding participant and audience market, eSport industry reached a volume of 350 million dollars in 2016, and a 700-million-dollar volume in 2017 [28]. Despite this economic development, since the mobile eSport market is still young and its competitive level is low, it provides great opportunities for game developers [29].

\section{Results and Recommendations}

The most popular mobile eSport applications were examined at a global scale in the present study. In this context, the following findings were achieved: 
- When the most popular mobile eSport applications were examined at a global scale, it was determined that with football ranking the first, basketball, billiards, badminton, skateboarding, golf and dart attracted attention.

- It was concluded that the interest in Mobile eSport applications differed according to countries.

- It was also concluded that this interest in Mobile eSport applications differed according their being free or paid.

- It was determined that the interest in Mobile eSport applications differed according to those who used App Store and Google Play Store application market.

In the present study, a certain date was set, and the interest in mobile eSport applications was examined on this specific date. New future studies may be designed covering different periods. In this way, findings may be obtained on the change of the interest in mobile eSport applications according to time. The findings of the present study and similar studies may be guiding for system/software developers in that they analyze the present status and reveal the relevant needs. In addition, new studies can be made to analyze mobile education applications by using the data collection method that is followed in the study. Educational activities for students' mental and psychomotor development can be supported through mobile eSpor applications. At this point, mobile eSpor applications can be included in the current education curriculum. The education curricula of countries such as USA, Sweden and Norway can be examined to make spreading mobile eSpor applications possible.

\section{REFERENCES}

[1] H. Böhmer, B. Hecht, J. Schönning, A. Krüger, G. Bauer. Falling asleep with Angry Birds Facebook on kindle: A large scale study on mobile application usage. $13^{\text {th }}$ International Conference on Human Computer Interaction with Mobile Devices and Services, Sweden, 47-56, 2011.

[2] K.W. Lim, L. Tabourier, B. Tebbani. Characterizing and predicting mobile application usage, Computer Communication, No.95, 82-94, 2016.

[3] Ş. Özdemir, E. Akadal, S. Çelik, A.Z. Reis. Uygulama marketlerinin eğitim kategorisi altındaki uygulamalarının incelenmesi, Akademik Bilişim, Antalya, Türkiye, 2013.

[4] J. Pouster. Smartphone ownership and internet usage continues to climbing emerging economies (2016). Online Available: http://www.pewglobal.org/files/2016/2002/pew_research center_global_technology_report_final_february_2022_ $\overline{2}$ 016.pdf

[5] K. Olmstead, M. Atkinson. Apps permission in the Goggle play store (2015). Online Available: http://www.pewinternet. org/files/2015/2011/PI_2015-2011-2010_apps-permissions FINAL.pdf.

[6] Statista. Number of apps available in leading app stores as of June 2016. Online Available: http:/www.statista.com/statistics/276623/number-of-appsa vailable-in-leading-app-stores/.

[7] L. Jozwiak. Advanced mobile and wearable systems, Microprocessors and Microsystems, No.57, 2002-221, 2017.

[8] J. Hamari, M. Sjöblom. What is a eSport and why do people watch it? Internet Research, Vol.27 No.2, 211-232, 2017.

[9] S.E. Jenny, R.D. Manning, M.C. Keiper, T.W. Olrich. Virtual(ly) athletes: Where eSport fit within the definition of sport, Quest, Vol.69, No.1, 1-18, 2017.

[10] E. Witkowski. On the digital playing field: How we do sport? With networked computer games, Games and Culture, Vol.7, No.5, 349-347, 2012.

[11] M.G. Wagner. On the scientific relevance of eSports, International Conference on Internet Computing, Las Vegas, USA, 26-29, 2006.

[12] M.G. Wagner. Competing in metagame game spaces: sSports as the first professionalized computer metagames, In. F. Von Borries, S.P. Walz, M. Boettger, D. Davidson, H. Kelley, J. Keucklich (Eds). Space time play: Sunergies between computer games, architecture and urbanism: The next level. Pp.182-185, New York, Springer, 2007.

[13] P. Bourdieu. Distinction: A Social Critique of the Judgement of Taste, Cambridge, Horward University Press, 1984.

[14] T. Taylor. Raising the Stakes: eSports and The Professionalization of Computer Gaming, Cambridge, MIT Press, 2012

[15] Y. Seo, J. Su. Beyond solitary play in computer games: The social practices of eSports, Journal of Consumer Culture, Vol.16, No.3, 635-655, 2016

[16] H.C. Aktuna, K. Ünlüönen. Yeni bir turizm çeşidi olarak elektronik spor turizmi, Gazi Üniversitesi Turizm Fakültesi Dergisi, No.2, 1-15, 2017.

[17] M. Üçüncüoğlu, V.O. Çakır. Modern spor kulüplerinin eSpor faaliyetlerine ilgi gösterme nedenleri üzerine bir araştırma, İnönü Üniversitesi Beden Eğitimi ve Spor Bilimleri Dergisi, Vol.4, No.2, 34-47, 2017.

[18] N. Işıkoğlu. Eğitimde nitel araştırma, Eğitim Araştırmalar Dergisi, Vol.20, No.3, 1-17, 2005.

[19] E. Karadağ. Eğitim bilimleri doktora tezlerinde kullanılan araştırma modelleri: Nitelik düzeyleri ve analitik hata tipleri, Kuram ve Uygulamada Eğitim Yönetimi, Vol.16, No.1, 49-71, 2010.

[20] A. Yıldırım, H. Şimşek. Sosyal Bilimlerde Nitel Araştırma Yöntemleri, Seçkin Yayıncılık, Ankara, 2016.

[21] C. Robson. Real Word Research, Blackwell, Oxford Press, 2001.

[22] R.T. Falkingham, R. Reeves. Context analysis: A technique 
for analyzing research in a field, applied to literature on the management of R\&D et the section level, Scientometrics, Vol.4, No.2, 97-121, 1998.

[23] E. Tavşancıl, E. Aslan. İçerik Analizi ve Uygulama Örnekleri, Epsilon Yayınları, İstanbul, 2001.

[24] D.C. Funk, A.D. Pizzo, B.J. Baker. eSport management: Embracing eSport education and research opportunities, Sport Management Review, No.21, 7-13, 2018.

[25] R. Li. Good Luck Have Fun: The Rise of eSports, New York, Skyhorse Publication, 2016.

[26] M. Martoncik. eSports: Playing just for fun or playing to satisfy life goals? Computers in Human Behavior, No.48, 208-211, 2015.

[27] Espor nedir? Online Available: http://5mid.com/espor-nedir

[28] Newzoo (2017). 2017 Global eSports market report. Online Available: from

http://resources.newzoo.com/hubfs/Reports/

Newzoo_Free_2017_Global_Esports_Market_Report.pdf? ].

[29] Why mobile is appealing? Online Available: www.imgawards.com/news/industry/mobile-gaming-futur e-eSports 